\title{
Quality of life of bipolar patients
}

\section{Maria Luisa Figueira}

\author{
Address: Department of Psychiatry, Faculty of Medicine, University of Lisbon, Lisbon, Portugal \\ from International Society on Brain and Behaviour: 3rd International Congress on Brain and Behaviour \\ Thessaloniki, Greece. 28 November - 2 December 2007 \\ Published: 17 April 2008 \\ Annals of General Psychiatry 2008, 7(Suppl I):S66 doi:I0.II86/I744-859X-7-SI-S66
}

This abstract is available from: http://www.annals-general-psychiatry.com/content/7/SI/S66

(C) 2008 Figueira; licensee BioMed Central Ltd.

Several studies have examined QoL in patients with major depressive disorder (MDD), and few studies have evaluated the impact of bipolar disorder on health-related quality of life. Namjoshi and colleagues assessed all relevant English-language articles published prior to 1999, identifying 10 studies for inclusion: quite heterogeneous; a variety of generic and depression-specific instruments to assess different aspects of HRQOL; rarely included descriptions of the psychometric properties of the instruments; small samples. Second review (Dean et. al. 2004) examined studies that had assessed HRQOL, workimpairment or healthcare costs and utilization in BDP published prior to November 2002; Using a broad definition of HRQOL (e.g studies that had assessed social or physical functioning in isolation) identified $65 \mathrm{HRQOL}$ articles. The described deficits in HRQOL in patients with BD were similar to those observed in patients with unipolar depression and equal or lower than levels of HRQOL observed in patients with other chronic medical conditions. Another comprehensive literature search in several databases up to November 2004 (e.g. MEDLINE, EMBASE, PubMed, PsychINFO, Cochrane Database) was performed by Michalak Erin E, et al., 2005. Several studies addressed the question how significant the QoL in patients with $\mathrm{BD}$ is related with the different stages of the disorder. They conclude that: BD type II reported significantly poorer HRQOL than BD type I in the areas of social functioning and mental health; women numerically lower scores in all of the questionnaire's domains except for mental health; the number of past episodes of depression was a stronger determinant of HRQOL than number of previous manic episodes; mania/hypomania patients significantly lower SF-12 mental health scores than euthymic patients? depressed or mixed patients significantly poorer HRQOL; depressed or experiencing a recent episode of depression; SF-36 scores remarkably low in the role-physical, vitality, social functioning, role-emotional and mental health sub-scales.

In our department using as instrument of measure the WHOQOL - brief, validated for the Portuguese population and the Brief Symptom Inventory in a sample of 53 Bipolar euthymic patients and a matched control sample of 53 subjects of the general population we found a good internal consistency in the domains of : physical well being, psychological quality of Life, social relationships and environmental QL; a significant discrimination between the two samples. The poor QL of Bipolar patients was correlated with sub-clinic symptolatology, mainly in depression and anxiety symptoms.

\footnotetext{
References

I. Namjoshi MA, Buesching DP: Qual Life Res 2001.

2. Dean BB, et al:: Curr Med Res Opin 2004.

3. Michalak Erin E, et al.: 2005.

4. Cooke RG, et al.: J Affect Disord 1996.

5. Robb JC, Young LT, et al.: J Affect Disord 1998.

6. MacQueen GM, et al:: Acta Psychiatr Scand 2000.

7. Vojta C, et al.: Compr Psychiatry 200I.

8. Yatham LN, Lecrubier Y, et al.: Bipolar Disord 2004.
} 